\title{
The Performance as an Emergent Property of the Integration of ERP Systems in Organizations: Empirical Evidence from Two Moroccan Industries
}

\author{
Brahim Bighrissen \\ Ph.D Student, SIC Team \\ Research, ENCG, Agadir - \\ Morocco
}

\author{
Elmahdi Ettamiri \\ Ph.D Student, SIC Team \\ Research, ENCG, Agadir - \\ Morocco
}

\author{
Chihab Cherkaoui \\ Prof. Habilité, IRF-SIC \\ Laboratory, ENCG \& Faculty of \\ Sciences, Agadir - Morocco
}

\begin{abstract}
The interest in the impact of ERP system integration on business performance aroused a great debate which is not yet settled. Some studies emphasize a positive effect while others are based on the concept of Solow's productivity paradox and emphasize a negative effect of this investment on business performance. Our research attempts to position ourselves in this debate by enriching the literature review and empirically validating this link in the context of an emerging country which is Morocco.A qualitative research method based on a case study approach was chosen to study the ERP system impact on business performance of Two Moroccan Enterprise. The results suggest a enhancement in the three dimensions of performance in the both Moroccan Enterprises.
\end{abstract}

\section{Keywords}

Enterprise Resource Planning (ERP), Information Technologies (IT), Business Performance, Moroccan organization, case study approach

\section{INTRODUCTION}

The information has generated a deficit that arises from imperfect data available, the finiteness of treatment and the ambiguity of interpretations available to the decision maker. Many organizations have begun to realize the importance of data and information they create. It is very difficult today to believe an organization without pertinent information. Indeed, all business functions (accounting, management control, marketing, sales, production, purchasing, human resources, maintenance, or research, etc.) are now covered by an information system [1]. Everyone is affected by the data and information quality [2].

With incorrect or incomplete information for example, activity indicators may deviate from reality and lead to inappropriate decisions. In addition, with the expansion of the Internet, the image of the company may be impaired, particularly if the information published as the prices are not updated. This kind of problem is usually caused by the proliferation of software applications, their heterogeneity and the rising cost of maintenance. To avoid these problems, companies try to move from a functional organization to a customer-oriented process method. This new model requires the integration of key business processes and the setting up of a coherent information system ensuring the uniqueness of the information and access to it from all the functions of the company. These aspects are captured by ERP systems.

An Enterprise Resource Planning (ERP) system is an integrated computer application used to manage both internal and external resources of an organization. ERP systems are based on a series of integrated software modules and a single database. The database collects data from many applications and re-injected into various applications that can handle almost all the internal activities of the organization. When a new process generates new data, they are immediately reusable by other business processes. An ERP implies the concept of extended organization, which stresses the interdependence between organizations, including their coordination and synchronization. This interdependence is to improve the quality of services offered to customers, their efficiency and productivity.

ERP systems also allow the integration of various business functions that provide to each other data and information. For example, if a sales representative places an order, the system checks the customer's credit limit, delivery schedules, determine the best route and reserve products in stock.

Many approaches of the impact of ERP systems of organization's performance are presented in the literature. Some of these works present the impact of ERP as a tree dimensional approach: managerial, organizational, and strategic impact [3]. Others discuss the economical, financial, organizational and the human impact of the integration of ERP systems. Other conceptions such as that presented in [4] and [5], approaches the impact of ERP systems without a classification of these. For these authors, the benefits can be summarized as in a set of capabilities.

This paper aims to study the impact of the integration of an ERP system to enhance the performance in Two Moroccan organizations. We will begin by presenting some recent trends of The ERP Systems and a synthesis of literature on organization's performance, IT and performance and ERP and performance. In the second part of this paper, we will discuss some empirical evidence of the impact on ERP system on business performance in Two Moroccan companies using a qualitative approach based on case study .

\section{RECENT TRENDS OF ERP SYSTEMS}

In this section, we present some definition of ERP system; the architecture of ERP technology will be presented, some implementation Challenges are discussed. Finally, the status of ERP systems in Morocco will be described.

\subsection{ERP: An approach of the definition}

Concerning the definition of what is an ERP, it is important to note that there is no consensus about the used terminology, and there are several definitions in the literature.

Firstly, we can say that the term ERP comes from the English expression "Enterprise Resource Planning" which means a 
tool or a methodology used to manage internal and external resources.

Relating to the most specific definitions in the field, an ERP is sometimes defined as a software application, sometimes as a package, as a computer-based application or as a system. Even if the terms designate specific concepts, they are often used interchangeably. Reference [6] have focused its definition on the fact that the ERP system is both an Information Technology System and a subset of the IS. For this author, an ERP allows a comprehensive management of a company including human resources management, accounting and financial management, sales management, management of procurement, production management and logistics management (Fig. 1). Reference [7] present a more synthetic and abstract definition which presents ERPs as "software applications that are customizable and modular designed to integrate and optimize the business processes by providing a single and coherent repository and based on standard business rules". Reference [3] talk about Enterprise System Software (ESS) which consists principally of enterprise resource planning and customer relationship management (CRM). According to [8], "an ERP system is an integrated software system that manages the mainstream operations of an organization. ERP is often defined as standardized packaged software designed to integrate the entire value chain in the organization".

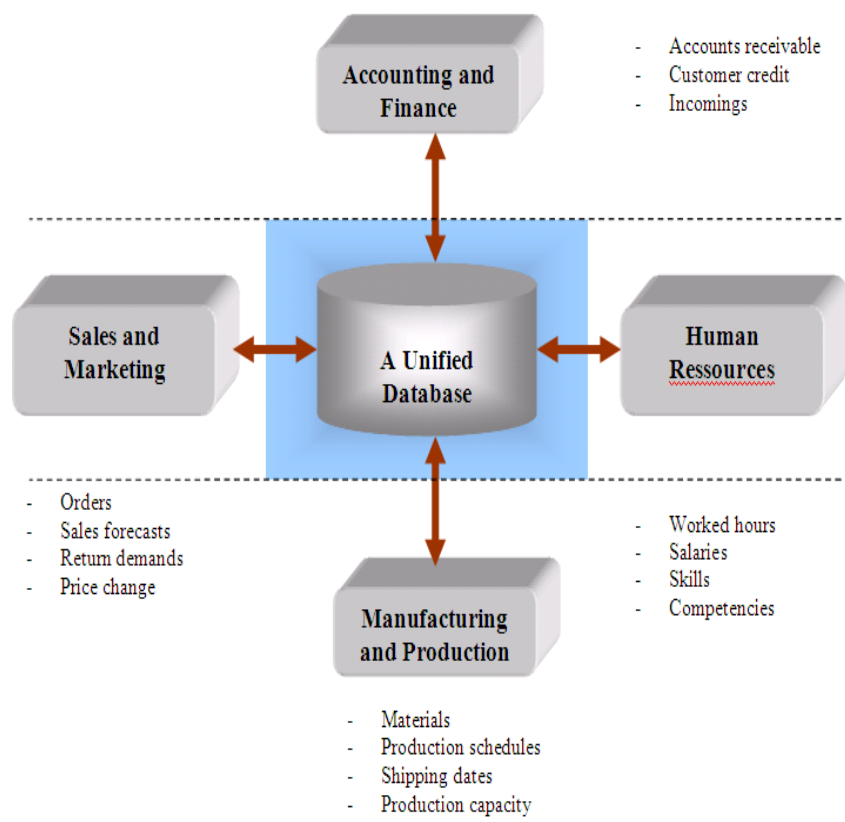

Fig 1: An Architecture of ERP Systems [9]

In short, although the terminology differs from one author to another, the common sense shows that ERP enable organization to integrate business processes and functions and supply managers at the same time with real time information to better manage their resources (both the internal and external) and to improve their decision making process. Throughout the rest of this paper, we use the term ERP system, firstly because it is widely used in the literature, and secondly an ERP is a particular IT, which inherits from the systemic approach to organization.

\subsection{ERP: A Technological Point of View}

One of the main characteristics of an ERP system is the centralization of all data from the business functions of an organization in a single unified relational database. An ERP includes a set of modules that covers all the processes of an organization.

Typically, an ERP system can either reside on a centralized server or be distributed across modular hardware and software units that provide "services" and communicate on a local area network. The distributed design allows a business to assemble modules from different vendors without the need for the placement of multiple copies of complex and expensive computer systems in areas which will not use their full capacity.

\subsection{The implementation Challenges}

The implementation of ERP solutions in an organization is not only to install software in the traditional way, but changing the structure and the management of the whole organization, implying a need to take into account a pipeline project change. Indeed the establishment of an ERP strategy requires structural changes, skills and behaviors.

The deployment of an ERP system can involve considerable business process analysis, employee retraining, and new work procedures. Several researchers have developed different models for ERP implementations. For instance, Reference [10] introduced a model of three phases: planning, project and enhancement. Other studies such that done by [11] illustrates that a road card of an ERP implementation consists of five stages: design, implementation, stabilization, continuous improvement and transformation. Implementing an ERP system is generally an extensive challenge, with a typical ERP implementation taking anywhere from one to five years [12]. The author adds that the performance of the organization will get worse before it gets better. Organizations are expected to encounter the resistance throughout the stages of ERP implementation.

The best practices [13] indicate that a successful implementation can force an organization to revalue its business practices and its processes and to concentrate on clearly definite objectives. To conclude, organizations have to be vigilant enough it comes to the question of implementing an ERP system. The implementation of ERP is a complex process that requires a new approach to project management and it is time consuming, it may take four to five years.

\subsection{ERP Systems Adoption in Moroccans Organizations}

In Morocco, ERP market is in full extension, the first major ERP projects were initiated in 1995. A multitude of European and American ERP vendors have settled on the market whose mission is to support the Moroccan companies to implement this type of project. Large companies have taken the step in adopting this technology.

In a survey of 61 largest Moroccan companies conducted in 2010 by the consulting firm called Capital consulting, more than $50 \%$ of the sample is focused on SAP and Oracle with $41 \%$ for SAP and $18 \%$ for Oracle. Over $12 \%$ of companies use ERP systems such as Dynamics, JDE with almost equivalent proportions.

\section{PERFORMANCE OF ORGANIZATIONS}

The great dictionary of the French terminology presents the performance of an organization as the degree of achievement of targets and objectives established by an organization [14], [15].This degree of achievement is generally measured by indicators. 
An exam of Research made in the management science shows that "organizational performance" is a recurring theme. The definition of this concept is the subject of several controversies; therefore, it will be essential to recall what its main variations are. Reference [16] and [14] distinguishes four main types of performance:

The strategic performance: consists of a long term strategic intent well as creating value for customers.

The Competitive performance: which comes from the competitive forces (the situational defence, changing the balance, anticipation of changes in the sector), market share, and the strategic gap (difference between performance desired and achieved).

The Socio-economic performance: refers to organizational performance (how the company is organized to achieve its objectives) or social performance (social reporting, sharing of profit).

The Economic and financial performance: which is shown through production, value added, gross operating surplus, gross operating income and net income.

With some similarities, reference [16] present four theoretical approaches to performance. The economic approach is based on the central notion of goal. The social approach highlights the human dimensions of the organization. The system approach measures the performance of the organization as a system. Finally, the political approach stresses that each individual can have its own criteria for evaluating performance. Finally, it is possible to define the performance through an approach aims (Performance level as to achieve objectives) and an approach means (performance as the ability to acquire resources) [17].

\section{IT AND PERFORMANCE}

In the literature analyzing the impact of IT on business performance, three main approaches can be distinguished: Causal Approach, Process Oriented View and Resource Based View.

\subsection{IT and Performance: causal relationship}

This approach stems from the early work of analyzing the contribution of IT to business value who sought to establish a direct link between investments in IT (independent variable) and the firm performance (dependent variable).

Some studies point to a positive effect while others are based on the concept of productivity paradox and highlight the negative effect of the investment on firm performance.

The mixed and sometimes contradictory results of studies of relationship between IT and performance gave rise to the productivity paradox of Robert Solow who stated that "we see computers everywhere except in the productivity statistics".

Reference [18] suggests four explanations for these contradictory results grouped into four categories: (1) Mismeasurement of outputs and inputs , (2) Lags due to learning and adjustment, (3) Redistribution and dissipation of profits, (4) Mismanagement of information and technology. In this sense, Reference [19] found that most U.S. banks have not made a profit after financial investment in IT in the 80s. They added that small banks showed no significant relationship between IT investment and performance. As for large banks, they posted negative returns after their investment in IT.
Some studies show positive effect of IT investment and performance. For example, Reference [20] found a positive relationship between the total investment in IT and performance, and this through a study of the European banking sector. It also shows that investment in technology services appears to have a positive impact on bank profits.

\subsection{IT and Performance: Process Oriented View}

Studies adopting Process Oriented View seeks to identify intermediate measures of performance and to determine the impact of IT on these measures.

Reference [21] believed that IT can have automational, informational and transformational effects on business processes at the operational and management levels .The automational effects refer to the efficiency perspective of value deriving from the role of IT as a capital asset being substituted for labor like productivity improvements, labor savings and cost reductions. The informational effects emerge primarily from IT's capacity to collect, store, process, and disseminate information and consist on consist on improved decision quality, employee empowerment, decreased use of resources, enhanced organizational effectiveness, and better quality. The transformational effects refer to the value deriving from IT's ability to facilitate and support process innovation and transformation and associate with reduced cycle times, improved responsiveness, downsizing, and service and product enhancement as a result of re-engineered processes and redesigned organizational structures.

\subsection{IT and Performance: Resource Based View}

The Resource-Based approach began to appear in the information technology evaluation in the mid-1990s. Many of works have tried to identify the different types of IT-based resources and to examine the relationship between these resources and the firm performance. For example, Reference [22] divided the IT resources into three categories: human resources, business resources and technological resources. By conducting an empirical study in the retail sector in the United States, they found that human resources related to IT is positively associated with firm performance, while technological resources seem to have no significant effect.

In another empirical research, Reference [23] proposed the concept of information technology capacity, defined as the ability to mobilize resources based on IT in combination with other resources and capabilities. This "IT capability" is built on tangible resources (components of the IT infrastructure), human resources (technical and managerial skills in IT) and intangible resources (customer orientation, knowledge capital, synergy ...). Reference [23] showed that IT capability is positively associated with organizational performance.

\section{ERP SYSTEMS AND PERFORMANCE}

As we discussed above, the ERP strategy is considered as a technology that could bring many benefits to organizations. Such benefits are expected to organize their overall functioning and make them more efficient.

The impact of ERP systems on the performance can be viewed from several angles and a lot of literature exists which discusses this subject. For example, reference [24] defines the performance as "the art of doing the right things." This aspect 
means the act of drawing the best part of available resources to achieve goals. Reference [25] considers that performance as an "emergent property that cannot be reduced to al sum of partial performance, but overall performance is based on a sequence between the economic and social issues and concern for the success long term."

The performance is thus considered as the sum of financial and non financial results. In this section we will have a synthetic view of the performance by presenting an approach based on three immediate impacts: the financial, the organizational and human performance.

\subsection{The Economic and financial performance}

By aligning IT applications, the installation of an ERP leads to a reduction in the overall applications [26]. This leads to optimize the cost of maintaining the information system due to the removal of interfaces and thus their cost of operations and maintenance. In ERP systems, the uniqueness of the database has the consequence of eliminating multiple entries and reducing the volume of information. This feature allows optimizing and deleting manual operations like: search, comparison and reconciliation.

Moreover, ERP can automate transactions, leading to reduced cycle time and improved operational productivity and quality. For example, customers will benefit from reduced time limits, lower prices and improved quality of the provided services. With ERP, the company can gain competitive advantage by offering low-cost prices and improving relations between the company and its customers, but also with the various stakeholders.

In addition, some studies like that presented by [27] analyse the ERP impact on financial performance by making a comparative analysis of the financial performance of ERP adopters and non-ERP adopters. They found that the financial performance of non adopters declined in time whereas the financial performance of adopters remained at an approximate constant level. To conclude, we say that ERP systems are expected to reduce operating costs (leading to improved ROI) by improving efficiency, productivity and therefore profitability through computerization.

\subsection{Organizational performance}

Authors like [28] show that the changes caused by an information system have an impact both on financial and organizational level on companies. ERP systems as a special case of IS does not constitute an exception to this logic. Indeed, the effects of ERP on the organization can include the impact on decision making, process control and the corporate culture. The ERP systems can change the structure of an organization by creating and reorganizing services. They also change the nature, movements and modes of information creation and communication [29].

Referring to the work of [30] and [31], we can identify some criteria for assessing organizational performance. We can mention among others: the quality of information flow, relationships between services, coordination, cooperation, the degree of control, communication, decentralization, flexibility, integration, etc.

For the criterion-related to the information quality for example, we can say as mentioned in [8], [32], [33] and [34] that this criteria has four immediate effects on organisational performance:
The Accuracy: The ERP modules help the companies to reduce human errors that often occur with manual practices. A major benefit of ERP systems for managers is to facilitate the gathering of important information for solving problems [35], [34];

The Timeliness: Reference [32] suggest that ERP systems have a decisive impact on the production (in real-time) of decision-making information. The ERP systems deliver more information faster than old systems. For example, the budgets can be calculated much faster [33] , [35], [36] ;

The Completeness: ERP, whose goal is the unification of information systems, is a factor of approximation of functions for more comprehensive information [36]- [38];

Consistency: ERP allow managers to have access to information of consistent management for better decision making.

\subsection{Human performance}

Recent research shows that human performance is analyzed through the results obtained by employees in a group, department or in an entire entity [31]. This result can be measured by the wealth created or the produced added value.

Obtaining a human performance depends on employees who add value by engaging their skills. The skills include the know-how, behavior, cooperation and creativity. With reference to the work of [16], here are some criteria for evaluating human performance like: productivity, commitment, skills, job satisfaction, leadership and training. The criterion that an ERP contribute to the improvement of staff knowledge has been validated by some works. Indeed, the introduction of ERP assumes that end users of this new technology must acquire new skills to better handle it. They thus reach a certain level of trust and efficiency in the use of ERP to enable them to improve their productivity.

We emphasize that the rest of these indicators has already been mentioned in the expected benefits of ERP. We therefore believe that successful integration of an ERP is assumed to satisfy at least some of those profits.

Other works such as [31], [39] adds that even if the performance and sustainability of organizations depends on factors and measurable goals, other factors called "intangible factors" are also important. Among these factors, we can mention the confidence in the future of the company, the strength of the culture of the company and its employees (shared values and how to meet customer expectations consistently), internal management organization and development of skills, innovative strength.

Generally, ERP enable organization to integrate business processes and functions and supply managers at the same time with real time information to better manage their resources (both the internal and external) and to improve their decision making process. It is supposed by some authors that by its benefits, it constitutes a vector for improving intangibles factors [31]. Also, some studies demonstrate through case studies that ERP is an innovation which can improve services and responsiveness and therefore gives confidence in the future of a company [40]

\section{METHODOLOGY RESEARCH}

In order to understand the impact of ERP system on business performance, the qualitative research method based on a case study approach was chosen. 
According to reference [41], the case method is a method of empirical research to study in depth a contemporary phenomenon within its context, especially when the boundaries between it and the object of study are not clearly delineated. This search method is based on several sources of data that must converge and the prior development of theoretical propositions to guide the collection and analysis of data. Direct contact of the interviewer and the interviewee implies a degree flexibility allowing the researcher to rephrase questions to clarify the meaning of words and expressions used and take into consideration non-verbal language of the interview at any time. The in-depth study of a case can provide a quantity of quality information on several aspects of the phenomenon.

At least four managers were interviewed in each company and a number of documents were collected as secondary data source. Indeed, In the company Alpha, The interviews were with the Chief Information Officer, Management Controller, Accounting Manager, Purchasing Manager. In the company Beta : the interviews were with Chief Information Officer, Accounting Manager, Purchasing Manager, Sales Manager. The interviews lasted between one and two hours.

\section{RESEARCH SETTING}

In what follows we will present a brief background of the two companies called Alpha and Beta in which we conducted the case study.

\subsection{Company Alpha}

Company Alpha, a subsidiary of a multinational company established in 13 countries is one of the major players in the kingdom in the area of construction.

In the interests of consistency and coherence, the multinational group started in 2000 the project implementation of SAP in all subsidiaries including Morocco.

This project coincided with the acquisition of a plant in another city that offers the opportunity to integrate this plant within the scope of implementation of SAP. The sake of consistency beyond the borders of Morocco, since each country has own these applications, it was necessary to develop a unique project for all subsidiaries.

Before the implementation of SAP R3, multiple applications coexist; we can cite CONCEPT for accounting and COSWIN for Inventory Management and CMMS. The existing software could cover just $48 \%$ of business processes. After the implementation of SAP, the SAP coverage is $95 \%$. Modules implemented: Accounting, Controlling, Purchasing Stocks, Maintenance, Sales, Production and Quality.

\subsection{Company Beta}

Company Beta is one of the leading companies in Morocco in the production and export of agricultural products. This company is located in the south of Morocco. It has more than 10 station conditioning throughout the kingdom. It is presented in international markets such as North America, UK, Continental Europe, Scandinavia and Russia Scandinavia and Russia through its offices of its representatives.

Certainly, Beta like other companies had gradually computerized most of its functions through software like Sage (purchase, sales, inventory and accounting) and other in house applications such as AGIRH for human resource management. Overall this computerization could not manage the flow of information by generating different services especially with the increase in production capacity and packaging. This situation was becoming intolerable especially for business managers. Prompting the company to opt for the implementation of Sage ERP X3 in 2003 to replace the various applications related to business processes. The different modules installed are those accounting, purchasing, sales and production.

\section{RESULTS AND DISCUSSION}

An examination of data from interviews with managers of the two companies mentioned above has identified several potential benefits provided by ERP systems. We are based on the three dimensions of performance to consolidate these benefits.

\subsection{ERP and financial and economic performance}

The results of our exploratory analysis show that the cost reduction, ease of sale transactions, budget tracking, inventory management and control purchases are the main indicators of financial and economic performance provided by ERP systems.

Both CIOs have entrusted us that following the implementation of ERP, IT costs are reduced. The management controller of Alpha confirmed that the reduction of operating costs is obtained by streamlining processes. He added that the implementation of ERP reduces Cost of goods sold (COGS). « The calculation of the COGS per product can provide answers to questions such as: Can we produce at this price level? Which most influences the cost? Now simply informing on the standard unit cost so that it automatically calculates COGS of each customer order»

With regard to the reduction in the cost of labor, the accounting manager of Alpha stated that ERP has reduced workforce from 50 to 16 due to a reorganization of work since operations are entered only once.

Another advantage is indicated by the sales manager of Beta is that the ERP system facilitates sales transactions and customer tracking. " ERP can track the the state of progress of relationships with clients and check if their demands were met on time ».

ERP can also keep track of the budget, according to the management controller of Alpha, each manager is responsible for budget. He can go to the information saving the degree of realization of budgets via the ERP system. «The system allows tracking monthly the budget, to make comparisons between what was done and what was expected, to report possible deviations and thus induce corrective decision making ».

According to the purchase manager of Beta, ERP system allows controlling the inventory level taking into account the outstanding orders and thus suggests the order quantities to maintain the level of stock at the optimum « This can lead to greater efficiency in inventory management like a reduction of storage costs».

The ERP system enables control of purchases and expenses, According to the purchasing manager of Beta , the company can optimize the management of daily operations ranging from taking orders or purchase to cover bills.

\subsection{ERP and organizational performance}

An examination of data from interviews with managers of the two companies has identified a number of potential benefits 
such as improved communication and coordination, reducing delays and information quality.

CIO of Alpha said that the ERP system enables better communication and coordination facilitated by the use of a single, common vocabulary. $\mathrm{He}$ added « Before the implementation of the ERP system, we have to deal with more complex coordination problems due to a large number of entities and an extensive spatial and temporal dimension». The management controller of Alpha illustrated the advantage of communication and coordination by saying this « the integration of the budget process in the ERP system induces an opportunity for rapprochement and cooperation between services ».

According to respondents, ERP reduces delays such as delays in obtaining information on the status of receptions and turnaround of orders. The accounting manager of Alpha stated that ERP system assists the managers in elaboration of accounting and financial statements monthly, statements of accounts and statements of daily payments by bank.

Moreover « real-time processing of data reduces the time of fence, which is an enormous advantage compared to older systems. «Tedious Works of very long period were facilitated and carried out in record time».

According to the management controller of Alpha «Before, we had to collect data at the source and it is not uncommon to wait several days and involve several people for the synthesis of a situation involving several functions and systems».

Interviewees also emphasized the quality of the information emphasizing that quality information is more detailed, complete, reliable, relevant and updated information.

Indeed, according to the accounting manager of Beta « products are analyzed independently and are reconciled with less detail. With the ERP system, all this is analyzed in detail ». He added «The ERP system provides detailed information, for example, for each supplier, you can view the details of transactions to date or only invoices not resulted compared to payments or information related to the perception of maturity errors, the amounts and methods of payment».

One of two CIO we met also stressed the information quality telling us that for his company, the information is complete. The management controller of Alpha stated « We must report regularly to the ERP system to provide us with a comprehensive overview of the various activities of the company in ordre to make management decisions at the right time».

ERP also generates reliable information. According to the management controller of Alpha «Before ERP, trying to understand the overall situation of the company, each unit has its own way of interpreting reality, ERP creates a single version that cannot be questioned because everyone is contributing to the system at the origin of results ». The CIO of Alpha added to this that « in case of error in the data, ERP system allows traceability and ensures that the correction will be well done to everyone».

Among the qualities of information discussed by our interviewees is that of relevance. He ERP system generates information that is well suited to their needs. According to the CIO of Alpha, the production manager can make requests in the ERP system to see how tocks and orders evolve this allows a better view of production planning. He added « Before ERP, many employees complain they do not know get out statistics, numerical reports or other printing they need, with the arrival of the ERP system, the problem is solved ». In addition, information from the ERP system procure to the sales manager the ability to perform cross analysis and establish statistics for detecting problems of dispersion of sales compared to orders, reducing turnover and delay and errors in deliveries.

Finally, the information is updated, accounting manager of Alpha stated that sales in quantity and in value become fully accessible data day to day. In addition, this module provides the calculation of the COGS from the confirmation of the order. He added, « After the expedition to an order, the system updates inventory records and sales history and transfers the financial data into General Ledger and Accounts Receivable files ».

\subsection{ERP and human performance}

The thematic analysis highlights some of the benefits provided by ERP systems and that are related to human performance such as development of user skills, their productivity and the increase their of responsibilities.

According to the CIO of Alpha, The ERP system generates new knowledge through the bringing together of previously unconnected data. It brings users to increase their functional versatility adding that their skills are expanded and their work is enriched. CIO of Beta argued that ERP system can also increase administrative productivity « the employee did not find any reason to delay an operation to make it. All things are automated and integrated into a single database unlike what was before ».

Another advantage falls under the human performance; it is the increase in responsibility. According to the CIO of Alpha, the informational responsibility of employees increases due to the uniqueness of the information " since they must imperatively encode the right information at the right time so that the other actors involved in the same process are able to perform their work ». In addition the system allows identification of responsible « Through the possibility to follow the path of the information to find out who did what and when ». Another respondent reported that users are aware that the use of ERP has made users more responsible and attentive. The input of incorrect information affects not only responsible for the input but also other users in the company.

\section{CONCLUSION}

This paper has started by presenting a synthetic review of literature on organization's performance.

The impact of IT on firm performance was reviewed. The impact of ERP systems on financial and economical performance, organizational performance and human performance was also discussed.

In order to study the impact of ERP system on Moroccan firm performance, a qualitative research method based on a case study approach was chosen. Eight managers were interviewed in two firms.

An examination of data from interviews showed the role of ERP systems in improving of Moroccan firm performance. Indeed, at the Economic and financial level, we found cost reduction, ease of sale transactions, budget tracking, inventory management and control purchases. At organizational performance, improved communication and coordination, reducing delays and information quality are the main impacts of ERP system on performance. At human level, the benefits provided by ERP systems were development of user skills, their productivity and the increase their responsibilities. 
However, it should be noted that this is a first exploratory reflection. This research should, indeed, be extended and verified by other empirical studies across a broad sample of companies from different industries and with different ERP systems implanted.

\section{REFERENCES}

[1] Brasseur, C. 2005. Data Management: Qualité des données et compétitivité, Ed. Hermes Science Publications.

[2] Loshin, D. 2001. Enterprise Knowledge Management: the Data Quality Approach, Ed. Morgan Kaufmann Publishers.

[3] Shang, S. and Seddon, B.P. 2002. Assessing and managing the benefits of enterprise systems: the business manager's perspective.Information Systems Journal, vol. 12 no. $4,271-299$.

[4] Olson, D. L. 2004. Managerial Issues of Enterprise Resource Planning Systems, Ed. McGraw-Hill Irwin.

[5] Tadinen, H. 2005. Human resources management aspects of Enterprise Resource Planning (ERP) Systems Projects. Master's Thesis in Advanced Financial Information Systems, Swedish School of Economics and Business Administration.

[6] Dubarry , P. and Bauvais, V. 1999. Retours d'expérience ERP . CIGREF, (Sept. 1999). 7-26,

[7] Pérotin, P. 2002. Mise en place des PGI et intégration organisationnelle in Proc.7éme colloque de l'AIM,

[8] Chapman, C. and Chua, W. F. 2000. Information technology, organizational form, and accounting. in Proc. EIASM second conference on new directions in management accounting: Innovations in Practice and Research. 193-211.

[9] Laudon, K. and Laudon, J. 2006. Management des systèmes d'information, Ed. Pearson Education, 2006.

[10] Parr, A. and Shanks, G. 2000. A model for ERP project implementation. Journal of Information Technology, no. 15. 289-303.

[11] Ross, J. W. 1999. Surprising Facts About Implementing ERP. IEEE IT Pro, (July -August.1999) .65-68.

[12] Poston, R. and Grabski, S. 2001. Financial impact of enterprise resource planning implementations. International Journal of Accounting Information Systems, vol. 2 no. 4.271-94.

[13] SAP. 2010. Implementing Entreprise Ressource Planning : lessons learned from the front, A SAP white paper, Available: http://www.sap.com.

[14] Marmuse, C. 1997. Performance. in Encyclopédie de gestion, Ed. Paris : Economica,. 2194-2208.

[15] Grand Dictionnaire Terminologique. 2002. Available: http://www. granddictionnaire. com /

[16] Morin, E., Savoie, A. and Beaudin, G. 1994. L'efficacité organisationnelle: théories, représentations et mesures, Ed. Montréal : Gaétan Morin,.

[17] Gauzente, C. 2000. Mesurer la performance des entreprises en l'absence d'indicateurs objectifs: quelle validité? Analyse de la pertinence de certains indicateurs. Finance Contrôle Stratégie, vol. 3 no. 2, 145-165.
[18] Brynjolfsson E. 1993. The Productivity Paradox of Information Technology. Communications of the ACM, vol.36, n. 2, p. 66-77.

[19] Markus M. L. and Soh C. 1993. Banking on Information Technology: Converting IT Spending into Firm Performance. Strategic Information Technology Management: Perspectives on Organizational Growth and Competitive Advantage,. 375-403.

[20] Becalli, E. 2007. Does IT investments improve bank performance? Evidence from Europe", Journal of banking and finance, Vol 31,. 2205-2230.

[21] Mooney, J.G., Gurbaxani and V., Kraemer, K.L.,1996. A Process Oriented Framework for Assessing the Business Value of Information Technology", The DATA BASE for Advances in Information Technology, Vol. 27, No. 2,. 68-81.

[22] Powell C.T. and Dent-Micaleff , 1997. A. Information technology as competitive advantage: the role of human, business, and technology resources", Strategic Management Journal, 18, 5, 375-405.

[23] Bharadwaj A., 2000. A resource-based perspective on information technology capability and firm performance: an empirical investigation", MIS Quarterly, 24, 1, 169196.

[24] Debiens, J. 1988. Comment augmenter la productivité dans le secteur public. Revue de gestion, vol. 13 . 1.6367.

[25] Bachet, D. 1998. Quelle performance pour les entreprises et pour l'emploi?. Revue Economie et Politique, (Nov Dec. 1998). 46-47,

[26] Marciniak, R. 1996. Management des projets informatiques : complexité et gestion des conflits. Système d'Information et Management, 1 1.1. 27-50.

[27] Hunton, J., Lippincott, B. and Reck, J. 2003. Enterprise resource planning (ERP) systems: Comparing firm performance of adopters and non-adopters. International Journal of Accounting Information Systems, . 4. 3, 165184

[28] Reix, R. 1999. Système d'Information et Management des Organisations.Ed. Paris : Vuibert,.

[29] Gomez, M-L. , Frot, B. and Duwer, A. 2002. Quels effets organisationnels pour les ERP. in Proc. AIMS, , 124.

[30] Kalika, M. 1988. Structure de l'entreprise, réalité, déterminants et performance .Ed. Paris : Economica,

[31] Chaabouni, J. 1992. le concept de performance dans les théories du management. in Proc. FSEG Sfax ,

[32] Spathis, C. and Constantinides, S. 2003. The usefull of ERP systems for effective management. Industrial Management \& Data systems, vol. 103 no. 9,. 677-85.

[33] Scapens, R. and Jazayeri, M. 2003. ERP systems and management accounting change: opportunities or impacts? A research note. European Accounting Review, vol. 12 no. $1, .201-233$.

[34] De Rongé, Y. 2000. L'impact des ERP sur le contrôle de gestion : une première évaluation. FINECO, no. 10,. 4564. 
[35] Granlund, M. and Malmi T. 2000. The Liberations and Limitations of ERP-systems for Management Accounting, Preliminary Draft. in Proc. 23 rd EAA Conference. 29-31.

[36] Ansari, S. and Euske, K. J. 1995. Breaking Down the Barriers Between Financial and Managerial Accounting : A Comment on the Jenkins Committee Report. Accounting Horizons, vol. 9, no. 2,. 40-43.

[37] Dumoulin, R. , La Villarmois, O. and Tondeur, H. 2001 Centre de services partagés versus externalisation: Solution alternative ou situation intermédiaire, le cas de la fonction comptable et financière. in Proc. 22 ème congré de l'AFC,. 1-28.
[38] Fourati, F. 2006. Veille stratégique : de l'évaluation de l'utilisation des agents intelligents à la prise de décision. Thèse de doctorat, Université Paris Dauphine,.

[39] Held. D. 2000. Le pari de l'intelligence (Cahiers de l'ASO, J.Y. Mercier),.116-123, Available: http://www.stephanehaefliger.com/campus/biblio/004/hle dc.pdf.

[40] Murphy , K.E. and Simon, S.J. 2002.Intangible benefits valuation in ERP projects. Information Systems Journal, no. $12, .301-320$.

[41] Yin, R. 2003. Case study research: design and methods, Thousand Oaks: Sage Publications. 